\title{
VENTILATION EFFICIENCIES OF A DESK-EDGE-MOUNTED TASK VENTILATION SYSTEM
}

\author{
D Faulkner* ${ }^{*}$, WJ Fisk, DP Sullivan, SM Lee \\ Indoor Environment Dept., Lawrence Berkeley National Lab, Berkeley, CA, USA
}

\begin{abstract}
In chamber experiments, we investigated the effectiveness of a task ventilation system with an air supply nozzle located underneath the front edge of a desk and directing air toward a heated mannequin seated at the desk. The task ventilation system provided outside air, while another ventilation system provided additional space cooling but no outside air. Test variables included the vertical angle of air supply $\left(-15^{\circ}\right.$ to $45^{\circ}$ from horizontal $)$, and the supply flow rate of (3.5 to $6.5 \mathrm{~L} \mathrm{~s}^{-1}$ ). Using the tracer gas step-up and step-down procedures, the measured air change effectiveness (i.e., exhaust air age divided by age of air at the mannequin's face) ranged from 1.4 to 2.7 , which is higher than typically reported for commercially available task ventilation or displacement ventilation systems.
\end{abstract}

\section{INDEX TERMS}

Ventilation rates and strategies, Offices, Improved IAQ practices and technologies, Perceived air quality

\section{INTRODUCTION}

Numerous studies have found that increased outside air ventilation rates in buildings are associated with reduced sick-building syndrome (SBS) health symptoms and with improvements in perceived air quality (Seppanen et al., 1999). Laboratory studies suggest that worker performance may improve with higher ventilation rates (Wargocki et al., 2000).

In general, increased ventilation rates will increase building energy use; therefore, technologies or practices that bring about the benefits of increased ventilation rates without energy penalties are highly desirable. One general approach for obtaining the benefits of increased ventilation rates without actually increasing the quantity of outside air supply or the associated energy use is to supply outside air in a manner that preferentially ventilates the breathing zone.

To quantify the benefits of such air supply methods, we use the air change effectiveness (ACE). The ACE is a measurable parameter used to compare the effective ventilation rate at the breathing zone to the effective ventilation rate that would occur throughout the building with thoroughly mixed indoor air at the same rate of outside air supply. ASHRAE (1997), defines the ACE based on ages of air as follows

$$
A C E=\frac{\tau_{n}}{\tau_{a v g}}
$$

\footnotetext{
* Contact author email: D_Faulkner@lbl.gov
} 
where $\tau_{\mathrm{n}}$ is the nominal ventilation time constant and $\tau_{\text {avg }}$ is the average age of air at the breathing zone. The average age of air at a location is the average time elapsed since air at that location entered the building. $\tau_{\mathrm{n}}$ equals the average age of air exiting the building which is identical to the indoor air volume divided by the rate of outside air supply. The practical interpretation is that ACE equals the effective ventilation rate at the location where people breathe divided by the ventilation rate that would occur throughout the ventilated space with perfect mixing. Consequently, we seek ventilation technologies with ACEs that are as high as possible.

In the U.S., traditional ventilation systems supply a mixture of outside and recirculated air in high velocity jets so that the indoor air in rooms is often well mixed and the ACE is approximately unity (Fisk et al. 1992, 1997; Olesen and Seelen 1992; Persily 1986; Persily and Dols 1989). Task-ambient conditioning (TAC) systems are a ventilation technology with the potential for improved ACE. TAC systems may supply air from the floor, desk, or partitions and enable occupants to adjust the supply flow rate, direction, or temperature so that thermal conditions can be tailored to meet the individual's requirements. Most TAC systems supply a mixture of outside and recirculated air in relatively high velocity jets. The mixing caused by the air recirculation and the jet-induced air motions prevent ACE values from substantially exceeding unity. However, in experiments using these systems to supply only outside air, ACE values were sometimes significantly above unity, but generally still below 1.3 (Faulkner et al. 1993, 1993b, 1999; Fisk et al. 1991)

In prior experiments (Faulkner et al. 1999), one TAC system designed to supply only outside air had relatively high values of ACE. This system supplied air horizontally toward the seated worker's torso from the underside of the desk top, with nozzles located approximately $70 \mathrm{~cm}$ from the occupant, and resulted in ACE values up to 1.4. The system could also supply air vertically toward the face from the front edge of the desk, leading to ACE values up to 1.9, but these very high ACE values only occurred with the mouth and nose located precisely within the supply jet.

Our current research seeks to identify air supply methods that provides consistently high values of ACE, for example by moving the outside air supply closer to the occupant and supplying air in low velocity jets. It is imperative that these air supply methods do not degrade thermal comfort, cause unacceptable drafts, or irritation at the face and eyes due to high air velocities. A similar research effort is underway at the Danish Technical University, with some promising results (Cermak and Majer 2000).

\section{METHODS}

The experimental system, illustrated in Figure 1, has a heated thermal mannequin seated at a desk, with a personal air supply of $100 \%$ outside air located beneath the keyboard. The desk and mannequin are located within a nearly airtight experimental room with a volume of $27 \mathrm{~m}^{3}$, located within a thermally conditioned, nearly constant temperature, laboratory.

For reliable evaluations of the Task Ventilation system, the experimental room must have realistic sources of indoor air motion and mixing. In this facility, air motion is driven by the heated mannequin, the heat release and fan of a personal computer, heat release from a computer monitor and overhead light, and by a recirculating air stream. The air supply jet of the Task Ventilation system provides additional indoor air movement. The mannequin is wrapped in electrically resistant media located beneath clothing, and the voltage supplied to the media was adjusted to produce a total rate of sensible heat generation of $75 \mathrm{~W}$, typical of 
the sensible energy release of an adult office worker. The energy consumed by the personal computer, monitor, and overhead light are $50 \mathrm{~W}, 62 \mathrm{~W}$, and $29 \mathrm{~W}$, respectively. The recirculating air stream (100\% recirculated air) has an air flow rate of $33 \mathrm{~L} \mathrm{~s}^{-1}$ equivalent to 4.4 indoor air volumes per hour, and represents the airflow that would typically be used to heat or cool rooms. Air exited the experimental room from the recirculated airstream. The exhaust flow rate was adjusted manually, using a damper, to keep the room pressurized by $\sim 1.5 \mathrm{~Pa}$.
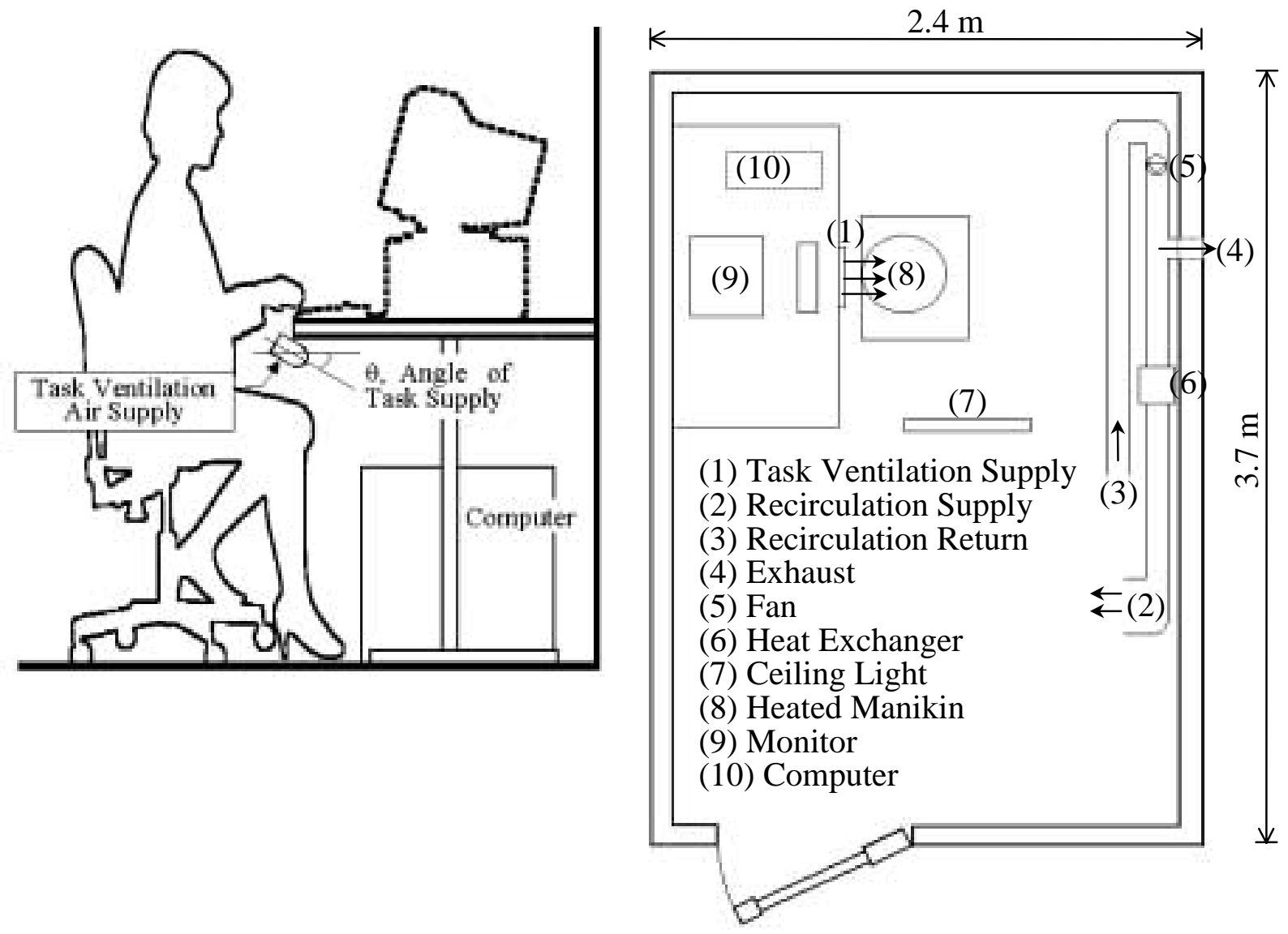

Figure 1. Side view of mannequin at desk in chamber and plan view of chamber with equipment identified.

The air supply nozzle of the Task Ventilation system was located beneath the front edge of the desk, about $10 \mathrm{~cm}$ from the mannequin. It was constructed from a $3.8 \mathrm{~cm}$ diameter PVC pipe with a slot, $3.8 \mathrm{~cm}$ high and $30.5 \mathrm{~cm}$ long. The slot was filled with a $3.2 \mathrm{~mm}$ per side hexagonal flow straightener. The angle of the nozzle was adjustable so that air could be directed from $-15^{\circ}\left(15^{\circ}\right.$ downward from horizontal) to $+45^{\circ}$ (see Figure 1$)$.

Our prior experiments (Faulkner et al. 1999) and those of Cermak and Majer (2000), plus airflow visualization studies, indicated that outside air supplied at a low velocity near the waist, will be entrained in the thermal plume flowing upward around the mannequin and thus, be transported to the region of the mouth and nose. The exit area of the nozzle is $116 \mathrm{~cm}^{2}$, resulting in a nominal air supply velocity of $0.3 \mathrm{~m} \mathrm{~s}^{-1}$ with a supply flow rate of $3.5 \mathrm{~L} \mathrm{~s}^{-1}$. With such a low supply velocity, the air supply jet, when at room temperature, can just be sensed if one places their hand between the nozzle and the mannequin. Velocities measured 
about $8 \mathrm{~cm}$ in front of the upper chest were typically less than $0.1 \mathrm{~m} \mathrm{~s}^{-1}$. The turbulence of the supply jet is reduced using a honeycomb flow straightener, because the theoretical work of Cermak and Majer (2000) suggests improved task ventilation system performance with reduced turbulence. A small heat exchanger located in the supply pipe for the Task Ventilation enabled the supply temperature to be reduced to as low as $17{ }^{\circ} \mathrm{C}$, about $5-6{ }^{\circ} \mathrm{C}$ less than the ambient room temperature.

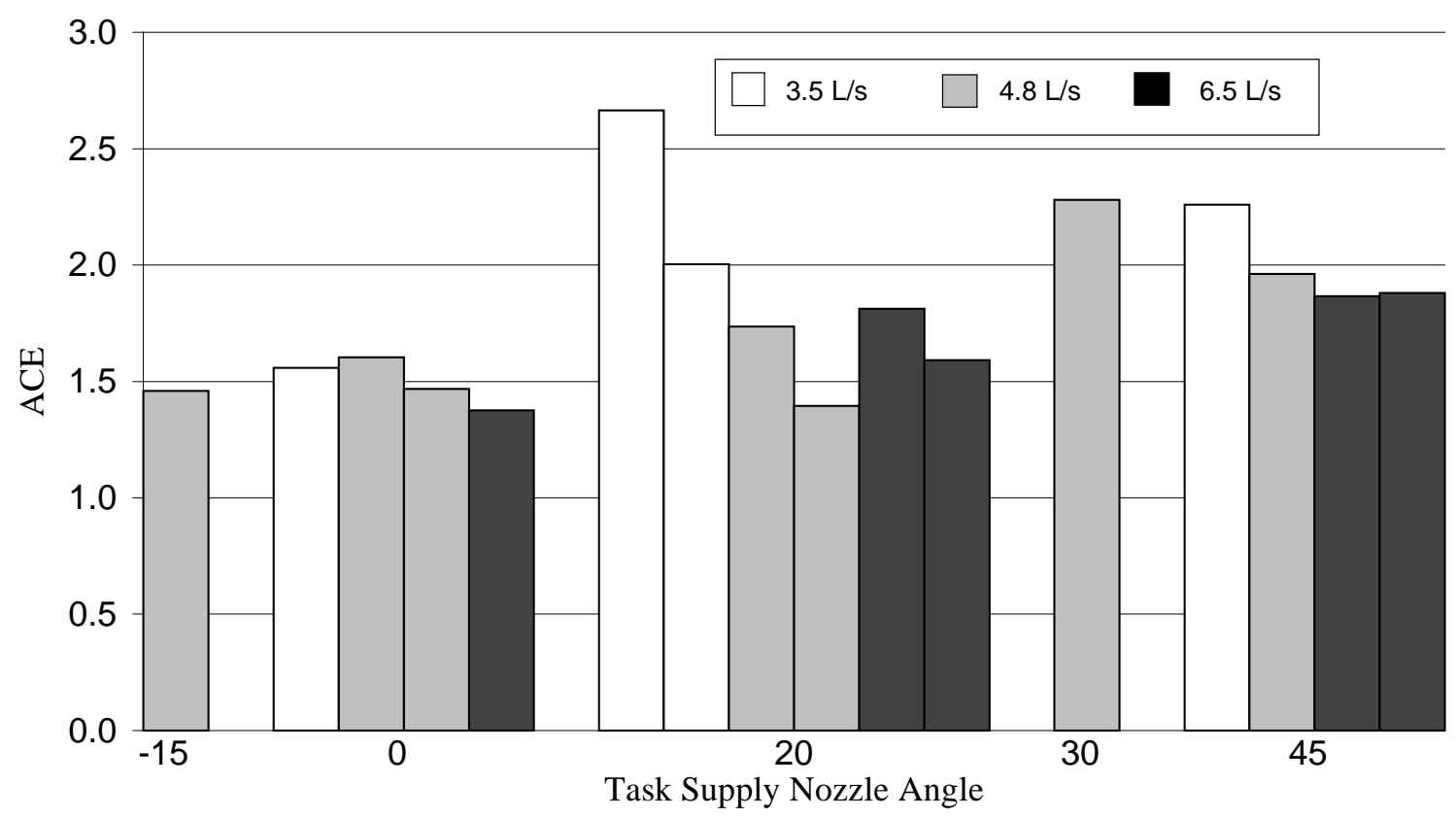

Figure 2. ACE values at outside air flow rates of 3.5, 4.8 and $6.5 \mathrm{~L} \mathrm{~s}^{-1}$ and task supply nozzle angles from $-15^{\circ}$ to $45^{\circ}$.

The ACE was measured using well-established tracer gas stepup or decay procedures (ASHRAE 1997). During tracer stepups, sulfur hexafluoride $\left(\mathrm{SF}_{6}\right)$ tracer gas was injected in the Task Supply pipe at a location upstream of the supply fan to increase mixing of the tracer within the airstream. The injection rate was maintained at a constant rate with a mass flow controller. Tracer gas injection continued for 3.5 to 9.5 hours, dependent upon the outside air flow rate. At the end of the stepups, $\mathrm{SF}_{6}$ concentration in the room's exhaust airstream was steady within the precision of our measurement system. For tracer gas decays, the tracer gas injection at the end of a stepup was stopped, allowing indoor $\mathrm{SF}_{6}$ concentrations to decay.

A quadrapole mass spectrometer with a multi-port valve was used to measure the tracer gas concentrations at 14 locations, every 2 minutes, around the mannequin and in the chamber. In this paper we concentrate on the measured concentrations at the mannequin's nose and in the chamber exhaust stream. The mass spectrometer was calibrated before each experiment with 20 calibration gases, and has a very linear calibration curve.

\section{RESULTS \& DISCUSSION}

A sample of results is provided in Figure 2. Measured values of ACE range from 1.4 to 2.7. With a positive air supply angle, the ACE was typically 1.7 or higher. These values of ACE 
are higher than typically measured in our prior studies of commercially available task ventilation systems and are also higher than typically reported for displacement ventilation systems. In a set of four repeat tests, the ACEs differed, on average, by 0.2. These results suggest that improved air supply technologies for task ventilation have a significant potential to improve IAQ at the breathing zone without increasing energy use.

Figure 2 illustrates a couple relationships that warrant comments. First, at a given flow rate, as the nozzle angle increases, the ACE increases also. As the nozzle angle increases so that it points more toward the mannequin's face, it provides upward momentum to carry the fresh outside air toward the breathing zone. There most likely is an optimum angle, possibly $30^{\circ}$ to $45^{\circ}$ for the nozzle angle to deliver the maximum ACE. This optimum angle may be dependent upon the flow rate.

The second observation is that ACE values tend to be greater at lower flow rates. This is important from an energy standpoint, as energy increases as outside air flow rates increases. Also, lower flow rates will less likely cause a problem with drafts. Again, there must be an optimum flow rate, since allowing the flow rate to go to zero will not increase the ACE indefinitely.

Additional research is underway to further optimize task ventilation air supply technologies and to assess the effects on comfort. We also plan to measure the ACE values experienced by people, as opposed to a thermal mannequin. We expect some reduction in ACE due to the movements of real people.

\section{CONCLUSIONS}

We have measured ACE values, 1.4 to 2.7, from a task ventilation system that consistently shows better ventilation effectiveness than our previous studies of task ventilation. These high ACE values have been achieved at relatively low flow rates and thus should provide energy savings as compared to conventional overhead ventilation systems. Based on limited temperature and air velocity measurements, we believe that thermal comfort has not been compromised to achieve high ACE values.

\section{ACKNOWLEDGEMENTS}

This work was supported by the Assistant Secretary for Energy Efficiency and Renewable Energy, Office of Building Technology, State and Community Programs, Office of Building Research and Standards of the U.S. Department of Energy (DOE) under contract No. DEAC03-76SF00098.

\section{REFERENCES}

ASHRAE. 1997. ANSI/ASHRAE 129-1997, Measuring air change effectiveness. American Society of Heating, Refrigerating, and Air Conditioning Engineers, Inc., Atlanta, GA. ASHRAE. 1999. ANSI/ASHRAE Standard 62-1999, Ventilation for acceptable indoor air quality. American Society of Heating, Refrigerating, and Air Conditioning Engineers, Inc. Atlanta, GA.

Cermak, R and Majer M. 2000. Development and evaluation of air terminal devices for personalized ventilation. ET-EP. 2000-09, Technical University of Denmark, Lyngby, Denmark.

Faulkner, D, Fisk, WJ, and Sullivan, DP. 1993. Indoor Air Flow and Pollutant Removal in a Room With Desk-Top Task Ventilation, ASHRAE Transactions 99(Pt. 2), pp. 750-758. 
Faulkner, D, Fisk, WJ, and Sullivan, DP. 1993b. Indoor Airflow and Pollutant Removal in a Room With Floor-Based Task Ventilation: Results of Additional Experiments, Building and Environment 30(3), pp. 323-332.

Faulkner, D, Fisk, WJ, Sullivan, DP, and Wyon, DP. 1999. Ventilation Efficiencies of DeskMounted Task/Ambient Conditioning Systems, Indoor Air 9(4): 273-281.

Fisk, WJ and Faulkner, D. 1992. Air Exchange Effectiveness in Office Buildings: Measurement Techniques and Results, Proceedings of the 1992 International Symposium on Room Air Convection and Ventilation Effectiveness, July 22-24, Tokyo, pp. 213-223, published by ASHRAE, Atlanta, GA.

Fisk, WJ, Faulkner, D, Pih, D, McNeel, PJ, Bauman, FS, and Arens, EA. 1991. Indoor Air Flow and Pollutant Removal in a Room with Task Ventilation, Indoor Air 1(3): 247-262.

Fisk, WJ, Faulkner, D, Sullivan, DP, and Bauman, FS. 1997. Air Change Effectiveness and Pollutant Removal Efficiency During Adverse Mixing Conditions, Indoor Air 7(1): 55-63.

Olesen, BW and Seelen, J. 1992. Field measurements of air change effectiveness using tracer gas techniques, IAQ'92, Environments for People, pp. 301-308, Published by ASHRAE, Atlanta, GA.

Persily, AK. 1986. Ventilation effectiveness measurements in an office building, Proceedings of IAQ'86, Managing Indoor Air for Health and Energy Conservation, pp. 548-567. Published by ASHRAE, Atlanta, GA.

Persily, AK and Dols, WS. (1989) "Field measurements of ventilation and ventilation effectiveness in an office/library building”, Indoor Air 1(3): 229-246.

Seppänen, OA, Fisk, WJ, and Mendell, MJ. 1999. Association of ventilation rates and $\mathrm{CO}_{2}$ concentrations with health and other human responses in commercial and institutional buildings. Indoor Air 9(4): 226-252.

Wargocki P, Wyon DP, Sundell J, Clausen G, and Fanger PO (2000) The effects of outdoor air supply rate in an office on perceived air quality, sick building syndrome (SBS) symptoms, and productivity. Indoor Air 10(4): 222-236. 